\title{
Aspects of Receptor Binding and Signalling of Interleukin-4 Investigated by Site-directed Mutagenesis and NMR Spectroscopy
}

\author{
Thomas Müller ${ }^{1}$, Thorsten Dieckmann², Walter Sebald ${ }^{1}$ \\ and Hartmut Oschkinat ${ }^{2} \dagger$ \\ ${ }^{1}$ Theodor-Boveri-Institut für Biowissenschaften (Biozentrum) \\ Universität Würzburg, Physiologische Chemie II \\ Am Hubland, D-97074 Würzburg, Germany \\ ${ }^{2}$ European Molecular Biology Laboratory \\ Meyerhofstr. 1, D-69012 Heidelberg, Germany
}

\begin{abstract}
Cytokines are hormones that carry information from cell to cell. This information is read from their surface upon binding to transmembrane receptors and by the subsequent initiation of receptor oligomerization. An influence on this process through mutagenesis on the hormone surface is highly desirable for medical reasons.

However, an understanding of hormone-receptor interactions requires insight into the structural changes introduced by the mutations. In this line structural studies on human IL-4 and the medically important IL-4 antagonists Y 124D and Y124G are presented. The site around Y124 is an important epitope responsible for the ability of IL-4 to cause a signa] in the target cells. It is shown that the local main-chain structure around residue 124 in the variants remains unchanged. A strategy is presented here which allows the study of these types of proteins and their variants by NMR which does not require carbon labelled samples.
\end{abstract}

Keywords: Interleukin-4; protein structure; NMR; signal transduction

\section{Introduction}

Interleukin-4 (IL-4 $\ddagger$ ) controls the growth and differentiation of a number of cells in the immune system (Paul \& Ohara, 1987; Paul, 1987, 1991; Jansen et al., 1990; Finkelman et al., 1990, 1991) by acting on receptors of the haematopoietin superfamily (Bazan, 1990a,b; Cosman et al., 1990). It belongs to a group of smaller cytokines with a molecular weight around $15 \mathrm{kDa}$ together with interleukin-3, interleukin-5 and the granulocyte macrophage-colony stimulating factor (GM-CSF) (Boulay \& Paul, 1992), and in contrast to, for example, the larger human growth hormone (hGH), erythropoietin and interleukin-6. IL-4 is secreted by

t Author to whom all correspondence should be addressed.

† Abbreviations used: IL-4, interleukin-4; GM-CSF, granulocyte macrophage-colony stimulating factor; Ig, immunoglobulin; hGH, human growth hormone; NOE, nuclear Overhauser enhancement; NOESY, nuclear Overhauser enhancement spectroscopy; TOCSY, total correlation spectroscopy; HMQC, heteronuclear multiple quantum coherence spectroscopy; COSY, correlation spectroscopy; TPPI, time proportional phase incrementation. class 2 helper T-lymphocytes, mast cells and thymocytes. Its major function is the stimulation of activated $B$-cells, and the initiation of the proliferation of $T$ lymphocytes, thymocytes and mast cells (Defrance et al., 1987). IL-4 acts also as an isotype switching factor in conjunction with interleukin-2 and interferon- $\gamma$ in immunoglobulin-mediated immune responses, discriminating between $\operatorname{Ig} \mathbf{E}$ and IgGl (de Vries et al., 1991; Vitetta et al., 1985; Coffman et al., 1986). This fact may be exploited for the treatment of allergic diseases (Burstein et al., 1991). Another important action of IL-4 is the induction of cytotoxic $\mathrm{CD}^{+} \mathbf{T}$ cells, which may serve as a basis for cancer therapy (Dullens \& DeWit, 1991; Tepper et al., 1989, 1992).

Mutagenesis experiments on II,-4 have been performed in order to characterize the regions important for its activity (Kruse et al., 1991, 1994; Morrison \& Leder, 1992) and to find variants with an antagonistic activity profile (Kruse et al., 1992). The variants showed either reduced binding affinity or were not able to activate the receptor, indicating a separation between binding and signalling. Mutagenesis studies of IL-4 related proteins to characterize the receptor binding sites have also been reported, e.g. interleukin-2 (Cantrell et al., 
1988; Weigel et al., 1989; Zurawski \& Zurawski, 1989), growth hormone (Cunningham \& Wells, 1989, 1991; Cunningham et al., 1991), GM-CSF and interleukin-5 (Sanderson et al., 1988; Shanafelt et al., 1991; Sakamaki et al., 1992).

Structural investigations have shown IL-4 as a four-helix bundle with an up-up-down-down arrangement of the four helices (Redfield et al. 1991). Four detailed structures of IL-4 have been published so far (Smith et al., 1992; Wlodawer et al., 1992; Powers et al., 1992b; Walter et al., 1992a), showing strong structural similarity between $\mathbf{I L}_{\mathbf{L}}-4$ and others such as GM-CSF (Diederichs et al., 1991; Walter et al., 1992b), IL-2 (Mott et al., 1992; McKay, 1992) and, to some extent, hGH (de Vos et al., 1992).

At present, only one IL-4 receptor molecule is fully characterized, comprising a single polypeptide chain of $\approx 800$ amino acid residues (Mosley et al., 1989; Galizzi et al., 1990; Harada et al., 1990; Idzerda et al., 1990). It occurs at the relatively low figure of 150 to 2500 molecules per target cell (Cabrillat et al., 1987; Park et al., 1987). A single dissociation constant of $\approx 100 \mathrm{pM}$ has been determined for the receptor-cytokine interaction. The IL-4 receptor is evolutionarily related to the large family of haematopoietin receptors, including receptors (or receptor subunits) for interleukins $2,3,5,6$ and 7, for GM-CSF and G-CSF and also for erythropoietin, growth hormone and prolactine (Bazan, 1990a,b; Cosman et al., 1990). Recently, a second IL-4 receptor, which shows low affinity binding to II,-4 has been isolated from pre-B cells, but there is only limited sequence data available (Fanslow et al., 1993).

The initiation of the signal transduction chain by the lymphokines is thought to proceed through oligomerization of at least two like or two unlike transmembrane receptor molecules, where the hormone interacts with the outer cell components, and the signal is transmitted to inside the cell upon oligomerization (Bazan, 1990a; Watowich et al., 1991; Cunningham et al., 1991). The positions of the receptor binding sites on the lymphokines deduced from mutagenesis studies were supported by the structure of the hGH receptor complex (de Vos et al., 1992) in which it is seen that one of two like receptor molecules binds to the A-C face of the fourhelix bundle, and the other to the A-D face. For interleukin-3, interleukin-5 and GM-CSF, it is known that an $\alpha$-subunit of a heterodimeric receptor binds specifically to the hormone, and that the $\beta$-subunit forms a complex only with the hormone/ $\alpha$-chain adduct (Hayashida, 1990; Fukunaga et al., 1990; Kastelein \& Shanafelt, 1993). In the past it has been proposed that IL-4 mediates the dimerization of two like receptor molecules, as has been established for the growth hormone (Paul, 1991; Bamborough et al., 1993; Wlodawer et al., 1993). However, the formation of homodimers has not yet been demonstrated for the high-affinity IL-4 receptor reported to date. Also, with the advent of a second IL-4 receptor (Fanslow et al., 1993), a heterooligomeric system becomes more likely.
In the light of this discussion and with the aim of designing further potential antagonists, the following issues are addressed in this paper: (1) a characterization of the major epitope responsible for signalling through the investigation of the variants Y124G and Y124D; (2) the identification of further residues building the epitopes responsible for receptor binding; and (3) a characterization of the mode of receptor oligomerization, in particular, with respect to the potential formation of homo- or heterodimeric receptor complexes.

Thus, the structure of IL-4 and the results of the investigations of the variants are discussed in terms of possible modes of hormone/receptor interactions. This discussion is based on the strong sequence similarity between the known IL-4 receptor and the human growth hormone receptor, for which structural data are available.

\section{Materials and Methods}

A method was employed for the structural investigation of the wild-type IL-4 and the variants Y124D and Y124G which does not rely on ${ }^{13} \mathrm{C}$-labelling as commonly used for such proteins (Powers et al., 1992a; Garrett et al., 1992). Instead, a set of ${ }^{15} \mathrm{~N}$-NOESY HMQC, ${ }^{15} \mathrm{~N}$-TOCSY HMQC (Marion et al., 1989) and 3D-TOCSY-NOESY (Oschkinat et al., 1990) spectra was used for the assignment of the resonances and the interpretation of the NOESY spectra. Most of the distances were determined from short mixing time NOESY spectra, enabling a more precise quantification of the NOEs. This approach was chosen to allow the investigation of those variants which are only expressed at low levels in Escherichia coli. The disadvantage of this method is that a smaller number of NOE is available in cases of severe spectral overlap, but this may be partly compensated for by the more precise measurement of the NOE which are available.

\section{(a) Samples}

Three samples of wild-type IL-4 were prepared. Two samples contained unlabelled IL-4, one was uniformly ${ }^{15} \mathrm{~N}$-labelled. Buffer conditions were $45 \mathrm{mM} \mathrm{NaOAc}-\mathrm{d} 3$, $10 \%{ }^{2} \mathrm{H}_{2} \mathrm{O} / 90 \% \mathrm{H}_{2} \mathrm{O}, \quad 0.2 \% \quad \mathrm{NaN}_{3}$, at $\mathrm{pH} 5 \cdot 3$. One unlabelled sample contained $10 \mathrm{mg}$ IL-4 in $600 \mu \mathrm{l}$, the ${ }^{15} \mathrm{~N}$-labelled sample contained $14 \mathrm{mg}$ IL-4 in $600 \mu \mathrm{l}$ buffer. The second unlabelled sample contained $40 \mathrm{mg}$ IL-4 in $1.2 \mathrm{ml}$ with the same buffer, but at pH 5.5 and was measured in a $8 \mathrm{~mm}$ NMR tube. More dilute samples were prepared of the variants Y124G and Y124D. For the variant Y $124 \mathrm{G}, 18 \mathrm{mg}$ of protein were dissolved in $1.2 \mathrm{ml}$ of buffer, and $12 \mathrm{mg}$ in $600 \mu \mathrm{l}$ buffer for the variant Y124D.

\section{(b) NMR measurements}

All measurements were performed on a Bruker $600 \mathrm{MHz}$ AMX spectrometer at $303 \mathrm{~K}$, if not specified otherwise. TPPI was applied to achieve quadrature detection in the virtual dimensions. The $8 \mathrm{~mm}$ samples were measured on a commercial $8 \mathrm{~mm}$ selective ${ }^{1} \mathbf{H}$ probe (Bruker). The wild-type sample, in the $8 \mathrm{~mm}$ tube, was used to measure a set of 2D-spectra: COSY (Aue et al., 1976), TOCSY $\left(\tau_{\mathrm{m}}=27 \mathrm{~ms}\right)$ (Griesinger et al., 1988), NOESY ( $\tau_{m}=10,20 \mathrm{~ms}$, with a long relaxation delay), all with presaturation, NOESY $\left(\tau_{\mathrm{rm}}=80 \mathrm{~ms}\right)$ with a jumpreturn read pulse (Jeener et al., 1979), and a 3D-TOCSY- 
NOESY $\left(\tau_{m}\right.$ TOCSY $=27 \mathrm{~ms}, \tau_{m}$ NOESY $\left.=100 \mathrm{~ms}\right)$ spectrum. The $2 D$ spectra were typically recorded with a spectral width of $8333 \mathrm{~Hz}, 1024 / 2048$ data points in $t_{1} / t_{2}$, and using a Bl-field of $20 \mathrm{kHz}$ for the TOCSY experiments. Zero quantum coherences were not suppressed in the NOESY spectra. The TOCSY-NOESY spectrum was recorded with $208 / 208 / 512$ data points in $t_{1} / t_{2} / t_{3}$, and with 16 scans per increment. This experiment took 7 days.

TOCSY, NOESY, ${ }^{15} \mathrm{~N}$-NOESY-HMQC $\left(\tau_{\mathrm{m}}=120 \mathrm{~ms}\right)$ and ${ }^{15} \mathrm{~N}$-TOCSY-HMQC $\left(\tau_{\mathrm{m}}=25 \mathrm{~ms}\right)$ spectra were recorded on the labelled wild-type sample. For the ${ }^{15} \mathrm{~N}$-NOESY-HMQC spectrum, 256/96/1024 data points were recorded in $F_{1} / F_{2} / F_{3}$, whereas $256 / 96 / 512$ data points were recorded for the ${ }^{15} \mathrm{~N}$-TOCSY-HMQC. In the latter case, only the $\mathrm{NH}$-region was recorded in $\mathrm{F}_{3}$. A spectral width of $3164.6 \mathrm{~Hz}$ was chosen for the nitrogen dimension.

A set of $2 D$ spectra as described above was also recorded on the unlabelled wild-type sample, in the $5 \mathrm{~mm}$ tube, at $308 \mathrm{~K}$.

The TOCSY-NOESY spectrum was processed in subcubes of the 512/512/512 data points used for the whole spectrum. Ijinear prediction was applied to predict data points up to double the number of those recorded, and extensive baseline correction was applied to all 3 dimensions. The heteronuclear 3D-spectra were typically processed in subcubes of the 1024/256/1024 data points used for the full spectrum.

The $20 \mathrm{~ms}$ NOESY spectrum used for the quantitative evaluation was processed with the application of a Lorentz-to-Gauss transformation and zero-filled up to 4096 data points in both dimensions to obtain optimal line shapes. Baseline corrections were applied using a polynomial of order 5 . Cross peaks were integrated using the program AURELIA (Neidig et al., 1990). As an example for the quality of the $20 \mathrm{~ms}$ NOESY data, the

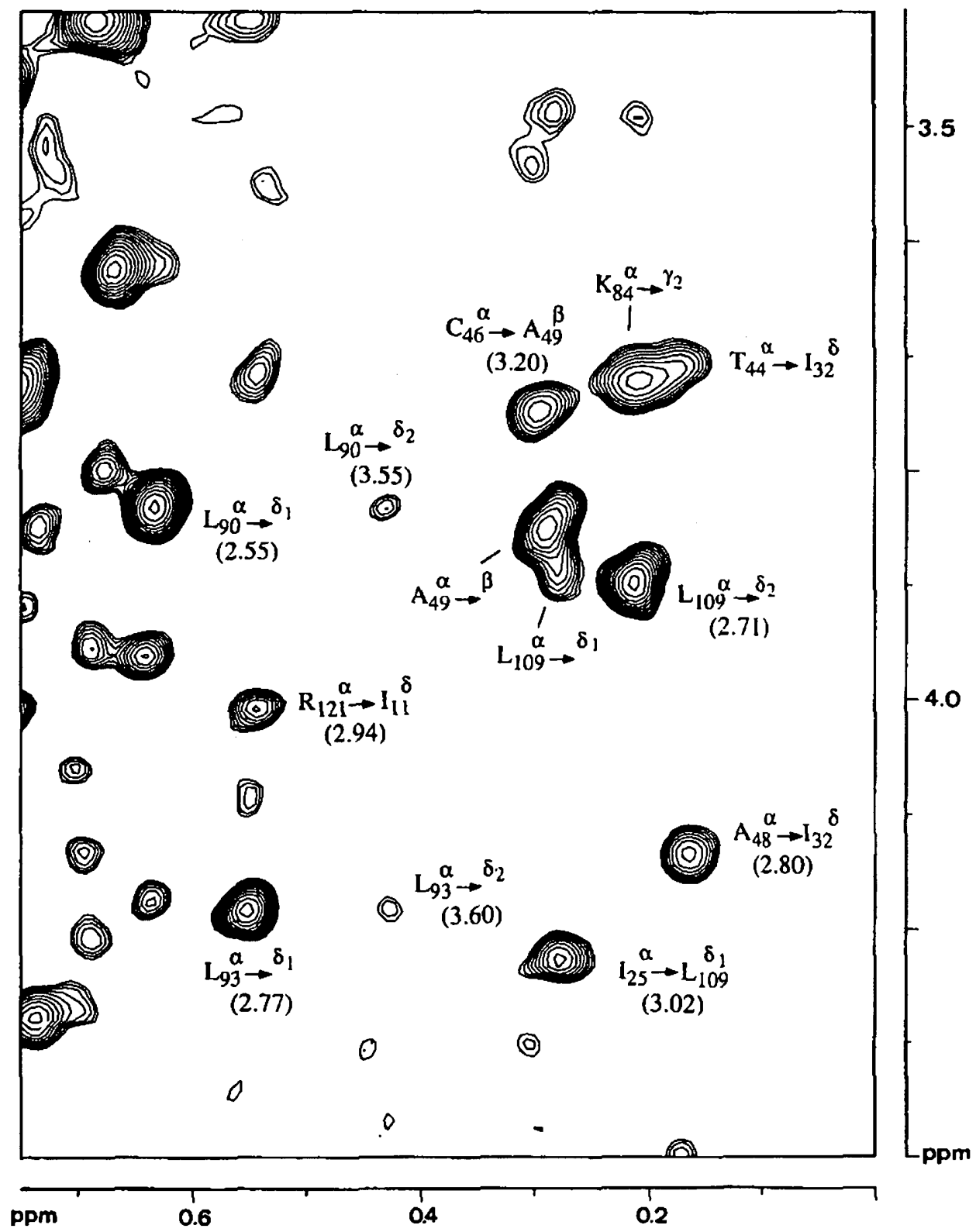

Figure 1. Region of the NOESY spectrum $\left(\tau_{\mathrm{m}}=20 \mathrm{~ms}\right)$ showing cross peaks involving $\mathrm{C}^{x} \mathrm{H}$ and methyl groups. The distances obtained from comparison of the signal intensities with those of reference NOF are given in parentheses. 
region with the $\mathrm{C}^{\delta} \mathrm{H}$ in $\mathrm{F}_{1}$ and the low-field methyl groups in $F_{2}$ is shown in Figure 1 .

\section{(c) Spectral assignments}

The assignment of the spin systems and the sequential assignments were obtained by conventional evaluation of COSY, TOCSY, and ${ }^{15} \mathrm{~N}$-NOESY-HMQC spectra together with the ${ }^{15} \mathrm{~N}$-TOCSY-HMQC spectrum (Marion et al., 1989). The evaluation of the TOCSY-NOESY spectrum helped to complete the assignment. Approximately 60 NOF of the NaN-and $\alpha \mathrm{NN}$-type (Oschkinat et al., 1990) were used for the sequential assignment, supplementing the data from the heteronuclear spectra. The results obtained were in line with the assignments reported in the literature (Redfield et al., 1991; Powers et al., 19926) except that the assignment of the methyl group proton resonances of $\mathrm{A} 49$ was very different to that obtained by Powers $e t$ al. In our spectra, the proton methyl signal occurs at a chemical shift of 0.28 p.p.m. It was assigned by means of COSY, TOCSY and NOESY cross peaks, and showed an unexpectedly large line width.

\section{(d) Assignment of NOE}

The NOE involving the amide protons were largely assigned using the ${ }^{15} \mathrm{~N}$-separated 3D-spectra. Other NOE were assigned with the help of a 3D-TOCSY-NOESY spectrum, which was evaluated using $F_{1} / F_{2}$-slices (TOCSY slices). It turned out to be most practical to scan the NOESY spectrum along the $F_{2}$-axis and to evaluate for each p.p.m. value the corresponding slices from the 3D spectrum with the same $F_{3}$-co-ordinate. An NOE with a certain $\mathrm{F}_{1}$-frequency in the $2 \mathrm{D}$-spectrum was then assigned by means of the $3 \mathrm{D}$ cross peaks in the $\mathrm{F}_{1} / \mathrm{F}_{2}$ slice with the same $F_{2}$-frequency. As a result, always one partner involved in the NOE (the one precessing in $t_{1}$ of the NOESY sequence) was characterized by 2 frequencies. In this way, assignments from the 2D TOCSY spectrum were used to assign the 3D-spectrum and the 2D NOESY. The assignment was unique when the signal in $F_{3}$ (or $F_{2}$ in the NOESY) was not overlapped by others in the IDspectrum, and the used TOCSY cross peak not superimposed by others in the $2 \mathrm{D}$ spectrum. In the case of overlapping signals in $F_{3}$, slices taken at the $F_{3}$ position of the partner involved in the NOE were inspected. It is in fact the symmetrical NOESY peak which is then observed to be dispersed into the third dimension by a coupling partner. This situation is similar to that which occurs during the evaluation of ${ }^{13} \mathrm{C}$-NOESY HMQC spectra. A slice of the 3D-TOCSY-NOESY spectrum taken at the $F_{3}$-frequency of the $V 29$ methyl group at 0.61 p.p.m. and the whole aliphatic region in $F_{1} / F_{2}$ is shown in Figure 2 . The signals belonging to the high-field methyl group of V29 show a number of NOE, which are mostly to Leu 109 , as indicated.

\section{(e) Quantification of NOE}

A build-up series of NOESY spectra was recorded to monitor the NOE curve for different types of NOE, e.g. NOE between geminal protons or between protons in the aromatic rings of the tyrosines. It turned out that a linear interpretation of the amplitudes was still possible in the spectrum recorded with a mixing time of $20 \mathrm{~ms}$. The NOF from the $20 \mathrm{~ms}$ NOESY spectrum were then calibrated with respect to averaged reference NOE of the same type (e.g. NH-aliphatic, aliphatic- $\mathrm{CH}_{3}$, etc). The following NOE were chosen as references: NOE between the amide protons in the side-chains of glutamine or asparagine; NOE inside the aromatic ring of the tryptophane; the NOE between two $\mathrm{C}^{\beta} \mathrm{H}$, NOE between $\mathrm{C}^{\alpha} \mathrm{H}$ and methyl groups in alanines or $\mathrm{C}^{\beta} \mathrm{H}$ and methyl groups in threonines; the NOE between aromatic protons in tyrosines; and the NOE between the methyl groups in valine or leucine. The largest distances observed varied from $3.0 \AA$ (NH-NH type) to $4 \cdot 2 \AA$ (aromatic-methyl NOE).

The error on the determined distances is composed of a statistical error due to spectral noise or artifacts, and systematical errors. For the latter, 2 major sources are expected: the effective correlation times for the internuclear vectors should vary over the protein, and the "initial rate approximation" could already be violated for some types of reference NOE. The variation of the local correlation time was therefore determined for a number of well-resolved reference NOE (around 10) for each type. The standard deviation was below $0.1 \AA$ except in one case; only the references taken from alanines and threonines showed a larger standard deviation $(<0.15 \AA)$. This is an unexpected result, as at least the side-chains of the asparagines and glutamines were expected to show different modes of motion. It was interpreted as an indication that the effective correlation times for the internuclear vectors are relatively similar for most of the residues in this 4-helix bundle protein, inclusive of the loop regions. A quenching of NOE was therefore not expected to be a major problem and lower bounds were used in the calculations. However, this approach is applicable only in this case due to the rigidity of the overal structure, where even the loops connecting the helices show only an intermediate degree of flexibility. Some classes of reference NOE were compared with each other to check whether the initial rate approximation was already violated. However, only negligible deviations were found.

For shorter distances ( $<3 \AA$ ) between backbone atoms (NH-NH, $\mathrm{C}^{x} \mathrm{H}-\mathrm{NH}$ ) error limits of $\pm 0.15 \AA$ were used These relatively narrow error margins were chosen because the values of the reference NOEs showed a small standard deviation and these kind of distances should be less affected by local motions. For the other distances error limits ranging from $\pm 0.21 \AA$ (for distances below $3 \AA$ not involving methyl groups) up to $\pm 0.35 \AA$ were used. The amplitudes of the cross peaks which could not be integrated due to partial spectral overlap were estimated by comparison with non-overlapped peaks. Much larger error limits were used for those, ranging from $+0.4 \AA$ to $+0.6 \AA$. A number of constraints were taken from the ${ }^{15} \mathrm{~N}$-NOFSY-HMQC spectrum or from the NOESY spectrum with a mixing time of $80 \mathrm{~ms}$; they were used in the calculations as upper limits only, and generous error margins were used. In total, 583 integrated and 248 estimated NOE were taken from the $20 \mathrm{~ms}$ NOESY spectrum, and 197 upper limit NOEs were taken from the spectra with longer mixing times.

\section{(f) Structure calculation}

The structures were calculated using the program XPLOR (Brünger, 1992). Prior to each calculation, an individual extended starting structure was generated. Apart from the NOE list, 120 mild dihedral angle restraints based on coupling constant information $\left(J_{\mathrm{HH}}\right.$ TOCSY experiment) (Willker \& Leibfritz, 1992) were included in the calculation. No hydrogen bond constraints were used. Standard 2-step simulated annealing protocols were applied (Nilges et al., 1991) including floating assignment. The first step consisted of 25,000 steps hightemperature dynamics (timestep $0.005 \mathrm{fs}$ ) at $2000 \mathrm{~K}$, followed by a cooling to $300 \mathrm{~K}$ and then energy minimization. In this phase, disulphide bonds were removed and substituted by appropriate NOE. The NOE forces were all 


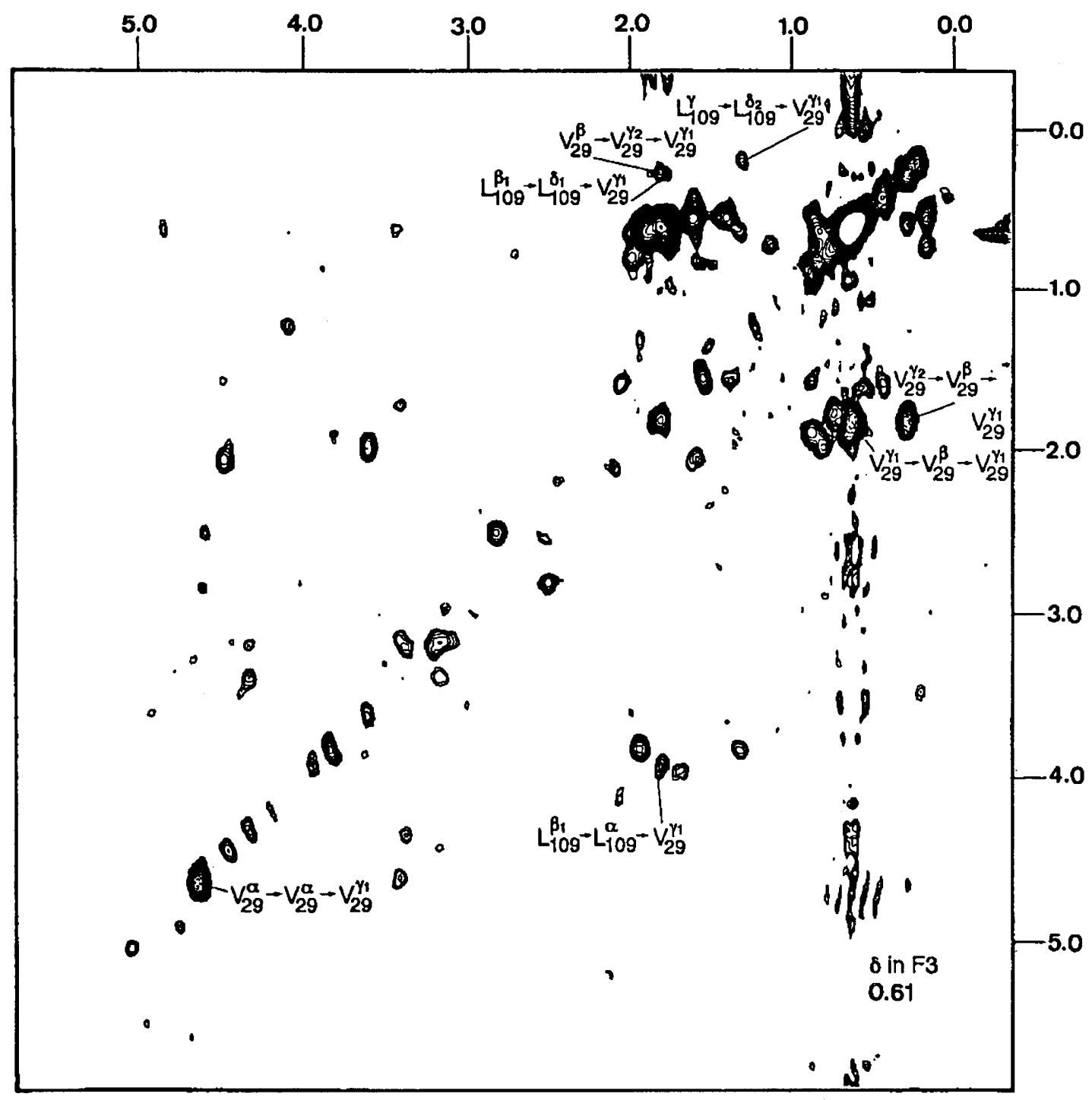

Figure 2. $F_{1} / F_{2}$-slice from the TOCSY-NOESY spectrum taken at the $F_{3}$-chemical shift of the low-field methyl group of Val29.

scaled down at the beginning, and then slowly increased. The second step of the protocol consisted again of a simulated annealing period $(8000$ steps at $2000 \mathrm{~K}$, timestep $0.005 \mathrm{fs}$ ), followed by 10,000 steps of cooling, in which the repulsive non-bonded interactions were scaled up to a normal level, and disulphide bonds included. A total of 70 structures of the wild-type were calculated, of which 32 were selected on the basis of the lowest global and NOE energy violations $\left(770\right.$ and $450 \mathrm{kcal} / \mathrm{mol} \AA^{2}$, respectively). In all, $40 \%$ of the selected structures showed no NOE violations larger than $0.4 \AA$, for all the other selected structures 1 or 2 violations in different places were observed.

\section{Results}

\section{(a) Wild-type structure}

The structures (Figure 3) of the wild-type IL-4 show a classical four helix-bundle topology with an up-up-down-down arrangement of the helices (named $A, B, C, D$ in sequential order). Two long loops occur between helices $A$ and $B$, and $C$ and $D$, respectively. These cross over each other and form a. short $\beta$-sheet at that point. The helices and the hydrophobic side-chains adopt rather well defined positions, as well as the $\beta$-sheet and some parts of the loops. The root-mean-square difference (r.m.s.d.) of the $\mathrm{C}^{\alpha}$-positions per residue between the 32 different structures is around $0.5 \AA$ for the $\alpha$-helical regions, the $\beta$-sheet, and the loop between the $\beta$-sheet and helix D (Table 1). All other loops are more disordered in our calculations, the r.m.s.d. per residue being around $2.5 \AA$. The least defined region comprises residues 37 to 39 and has a local r.m.s.d. of $3.5 \AA$. The side-chains of the hydrophilic amino acids are primarily located at the surface of the protein, so that only a few of them adopt defined positions in our structure. The structure agrees with those already reported. Large r.m.s.d. values are observed in those areas where an increased mobility was detected in the dynamics measurements of Redfield (Redfield et al., 1992). 


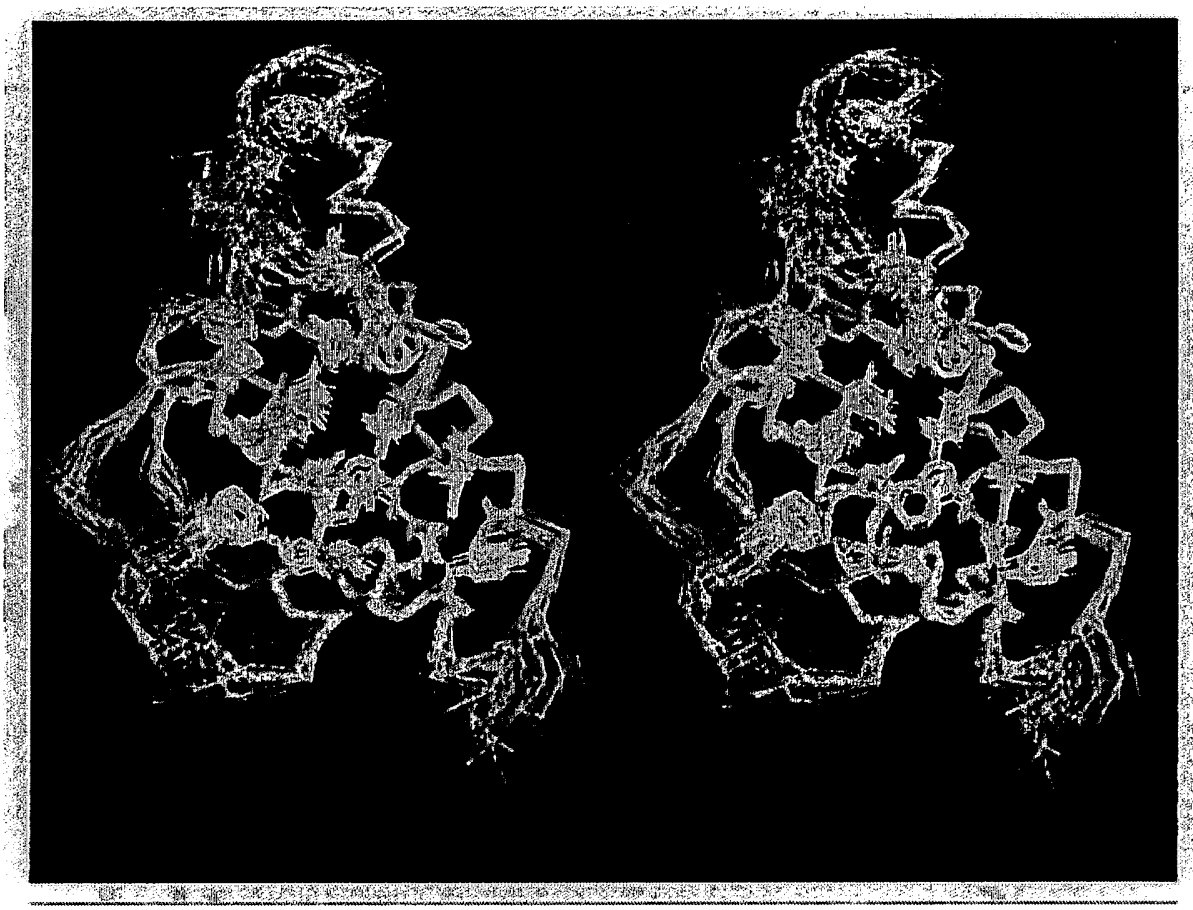

Figure 3. $\mathrm{C}^{a}$-plot of interleukin-4 including the side-chains of the hydrophobic amino acids (stereoplot). A total of 32 structures is shown.

A minimized average structure of the 32 calculated structures shown in Figure 3 was compared to the average structures of the two NMR investi-

Table 1

\begin{tabular}{lrl}
\hline A. Number of constraints & & \\
NOE & 1028 & \\
Intra-residue & 259 & \\
Sequential $(i, i+1)$ & 391 & \\
Medium range $(i, i+2,3)$ & 170 & \\
Long range & 208 & \\
Dihedral angles & 146 & \\
B. Structural statistics & & $(0.000058)$ \\
Deviations from idealized covalent geometry & \\
Bonds (A) & 0.045 & $(0.011)$ \\
Angles & $0.54^{\circ}$ & $(0.02)$ \\
Impropers & $0.40^{\circ}$ & $(0.0014)$ \\
NOE violations $(\AA)$ & 0.091 &
\end{tabular}

r.m.s.d. from the minimized average structure (mean value and standard deviations, backbone atoms) $(\AA)$

$\begin{array}{lll}\text { Helix A }(5-19) & 0.39 & (0.07) \\ \text { Helix B (41-59) } & 0.40 & (0.06) \\ \text { Helix C (7-93) } & 0.48 & (0.14) \\ \text { Helix D (109-125) } & 0.25 & (0.05) \\ \text { All helices } & 0.62 & (0.17) \\ \text { Residues 5-125 } & 1.92 & (0.201)\end{array}$

Residues 5-125

C. Struclure comparison

\begin{tabular}{lccc} 
& IITL $\rightarrow$ IRCB & I BBN $\rightarrow$ IRCB & Ours $\rightarrow 1$ RCB \\
& $(\AA)$ & $(\AA)$ & $(\AA)$ \\
5-125, bb & 1.59 & 1.30 & 1.58 \\
All helices, bb & 1.27 & 1.02 & 1.31 \\
88-98, bb & 1.00 & 1.07 & 0.84 \\
$\begin{array}{l}\text { dto, all heavy } \\
\text { atoms }\end{array}$ & 2.83 & 2.32 & 1.87 \\
$\begin{array}{l}\text { 5-14, 116-125, bb } \\
\text { dto, all heavy }\end{array}$ & 069 & 0.85 & 0.71 \\
atoms & & & \\
\hline
\end{tabular}

bb, backbone atoms: $\mathrm{N}, \mathrm{C}^{a}, \mathrm{C}^{\prime}$. gations available from the Brookhaven Data Bank, 1ITL (Smith et al., 1992), and 1BBN (Powers et al., 1993), as well as to a crystal structure, IRCB (Wlodawer et al., 1992) on the basis of r.m.s.d. values (Table 1). On the whole, the comparison of the NMR structures with each other and with the crystal structure IRCB shows a similar level of accuracy for the three NMR structures. Comparing backbone atoms $\left(\mathrm{C}^{\prime}, \mathrm{C}^{a}, \mathrm{~N}\right)$ for the residues 5 to 125 , the three NMR structures diverge by values of $1.30 \AA$ (lBBN), $1.58 \AA$ (our structure), and $1.59 \AA$ (IITL) from the X-ray structure (IRCB). Our structure shows an r.m.s.d. of 1.98 (IITL) and 1.68 (IBBN) to the other NMR structures. There are two individual regions which merit some closer inspection, that is the region with the tryptophan, whose position is highly dependent on the assignment of $\mathrm{A} 49$, and the region around tyrosine 124 . The region 88 to 98 of our structure shows a small, but significantly smaller r.m.s.d. to the $\mathrm{X}$-ray-structure $\mathrm{IRCB}$ when backbone atoms are compared, but a much better definition, when all heavy atoms are compared (Table 1). The reason for this is the considerable number of NOE between A49 and W91 found in our spectra. In fact, the position of the side-chain of W91 is exactly the same in our structure as in the $\mathrm{X}$-ray structure.

The structure around Y124 is important for the initiation of signal transduction and is hence a potential target for drug design. The area around this tyrosine $(5 \rightarrow 14,116 \rightarrow 125)$ deviates in our structure by $0.71 \AA$ from the X-ray structure, when backbone atoms are compared, and by $1 \cdot 79 \AA$, when all heavy atoms are compared. The other two NMR structures show similar deviations from the $\mathrm{X}$-ray structure (Table 1). The side-chain of Y124 is posi- 


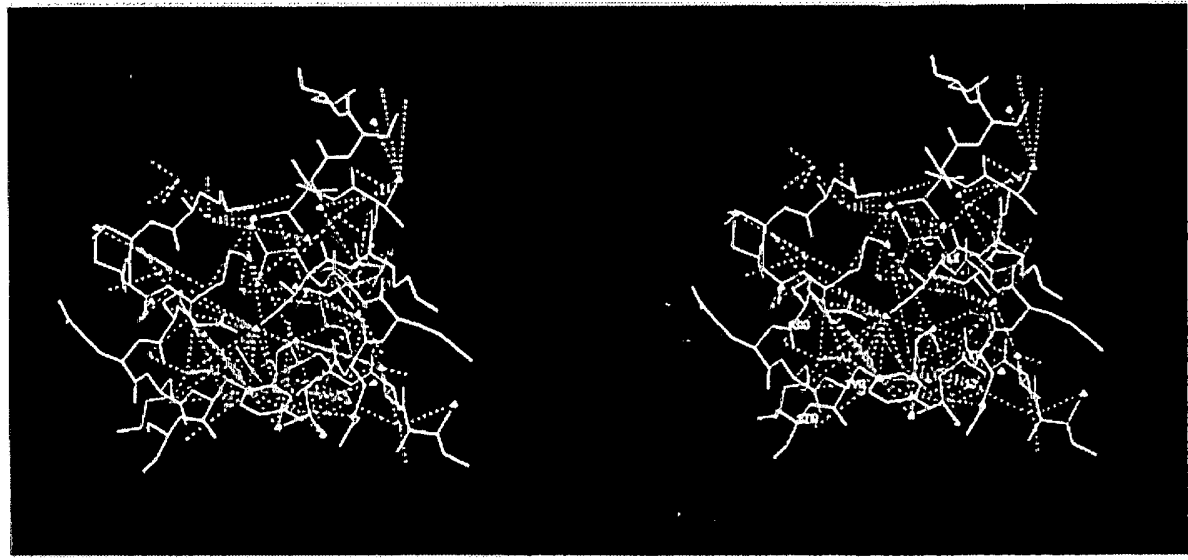

Figure 4. Enlargement of the region around Y124 taken from the minimized averaged structure (stereoplot). The medium and long range NOE defining this part of the structure are indicated by blue lines.

tioned in the contact area between helices $A$ and $D$, exposing part of the aromatic ring (approximately $40 \%$ ), and the $\mathrm{OH}$ group, to the solvent, forming a hydrophobic region on the surface of the protein. The position of Y124 is defined by hydrophobic interactions with the side-chains of $\mathrm{L7}$ and 111 , the latter also showing some solvent accessibility. On the surface around the site of Y124, a number of hydrophilic residues are positioned, i.e. R121, S125, and Q8. There is a considerable number of NOE involving Y124 (Figure 4, Table 2). Its ring is partly protected by the side-chains of $I 11$ and R121. The side-chain of R12l shows NOE between its $C^{\delta} \mathrm{H}$ and the $C^{\delta} \mathbf{H}$ methyl group of $\mathrm{Ill}$, which defines the position of its $\mathrm{C}^{\alpha}$ - $\mathrm{C}^{\delta}$-fragment. The guanidinium group, however, does not show any NOE to Y124, which would be expected from the $\mathrm{X}$-ray structure. In particular, the $\mathrm{N}^{\ell} \mathrm{H}$ of $\mathrm{R} 12 \mathrm{l}$ and the aromatic protons of Y124 should show strong NOE if a rigid structure, as present in the $\mathrm{X}$-ray structure involving a hydrogen bond between R121 and Q8,

Table 2

Long-range NOE between helices $A, C$ and $D$ around the mutation site

\begin{tabular}{llccc}
\hline A & C & wt & Y124G & Y124D \\
\hline Thr6 & Leu93 & $\mathrm{m}$ & $\mathrm{m}$ & $\mathrm{m}$ \\
Leu7 & Leu93 & $\mathrm{m}$ & $\mathrm{m}$ & $\mathrm{m}$ \\
Ile10 & Asn89 & $\mathrm{s}$ & $\mathrm{s}$ & $\mathrm{s}$ \\
Ile10 & Leu93 & $\mathrm{s}$ & $\mathrm{s} / \mathrm{m}$ & $\mathrm{s}$ \\
Thr13 & Phe82 & $\mathrm{s}$ & $\mathrm{s}$ & $\mathrm{s}$ \\
A & D & wt & Y124G & Y124D \\
\hline Ly8117 & Leu14 & $\mathrm{s}$ & $\mathrm{s}$ & $\mathrm{s}$ \\
Met120 & Ile11 & $\mathrm{w}$ & - & - \\
Met120 & Leul4 & $\mathrm{m}$ & $\mathrm{m}$ & $\mathrm{m}$ \\
Met120 & Leu93 & $\mathrm{m}$ & $?$ & $\mathrm{~m}$ \\
Arg121 & Ile11 & $\mathrm{s} / \mathrm{m}$ & $\mathrm{m}$ & $\mathrm{m}$ \\
X124(H $\alpha)$ & Leu7 & $\mathrm{m} / \mathrm{w}$ & $\mathrm{m} / \mathrm{w}$ & $\mathrm{w}$ \\
\hline
\end{tabular}

The intensity of the strongest NOE between the indicated residues is given ( $s$, strong; $m$, medium; $w$, weak; $s / m, w / m$, at the transition point; ?, not available due to spectral overlap; , not observed, probably for reasons of different signal/noise. would exist in solution. There are a number of NOF defining the orientations of helices $A, B, C$ and $D$ with respect to each other in this area (Table 2 ). These are the potential indicators for structural changes in the variants.

\section{(b) Variants $Y 124 G$ and $Y 124 D$}

The variants Y124G and Y124D were investigated to determine the nature of the structural changes resulting from these substitutions. The NMR spectra of both variants show similar chemical shifts for most of the residues compared to the wild-type, suggesting strong similarity in their overall structures. For both variants, larger chemical shift changes were only observed towards the $\mathrm{C}$ and $\mathrm{N}$ terminus. In fact, chemical shift deviations smaller than $0 \cdot 1$ p.p.m. are observed for the residues 11 to 120 of $\mathrm{Y} 124 \mathrm{G}$, indicating that no large-scale structural changes are present. Similar observations were made for Y124D. However, in the region of the substitution greater effects on the chemical shifts were observed. This is expected for the substitution of an aromatic side-chain as it has a large anisotropic effect.

The local NOE pattern of the regions 1 to 9 and 120 to 124 in the variant Y124G shows the conservation of $\alpha$-helical structures around the substitution site. The secondary structure appears to be identical to that of the wild-type, where helix A starts at I5, and the end of helix D can be located at S125. This is indicated for helix $\mathrm{A}$ by the sequential NOE of the type $\mathbf{N H}_{i} \mathbf{N H}_{i+1}$, as well as by the presence of the NOE of the type $\alpha_{i} \mathrm{NH}_{i+3}$, involving I5 and Q8 (Figure 5). Helix D extends up to S125, as can be concluded from the $\mathrm{NH}_{i} \mathbf{N H}_{i+1} \mathrm{NOE}$ observed, and from a number of long range NOF which are also found in the wild-type (Figure 4), involving for example L7 and G124 (Table 2).

The variant $Y 124 \mathrm{D}$ shows a pattern of secondary structure (Figure 5) and long range NOE for helices $A$ and $D$ which is similar to that of the wild-type and variant Y124G. A comparison of the very pronounced NOE of the type $\alpha_{a \beta i+3}$ between 


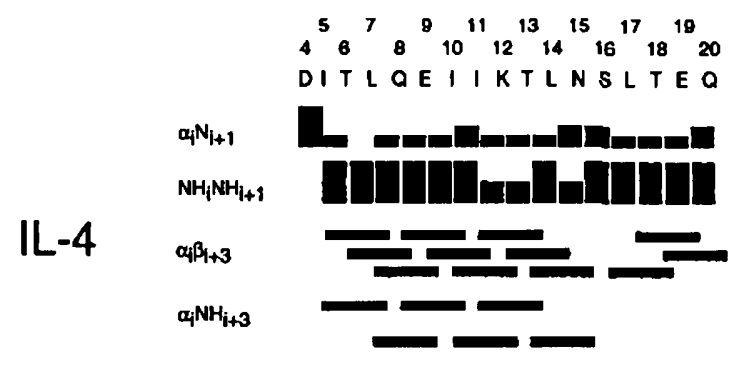

DITLOEIIKTLNSLTEO

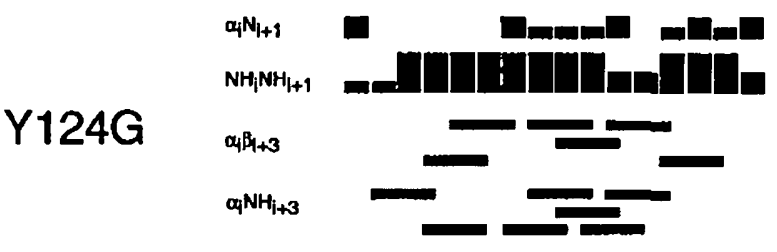

DITLOEIIKTLNSLTEO

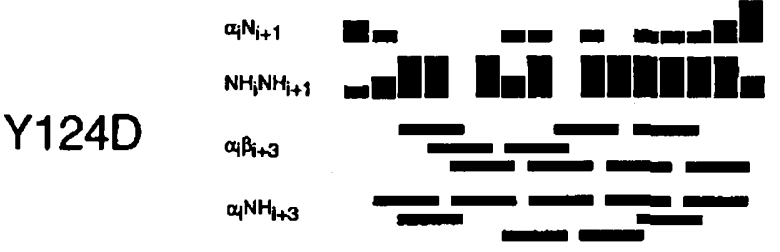

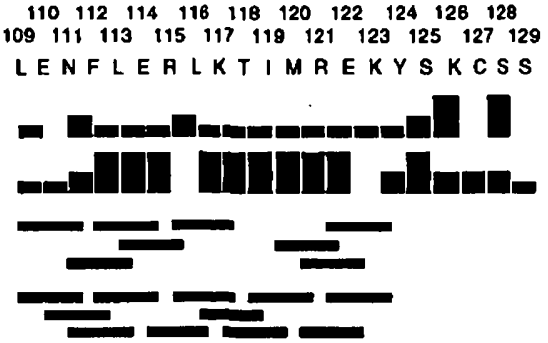

LENFLERLKTIMREKGSKCSS

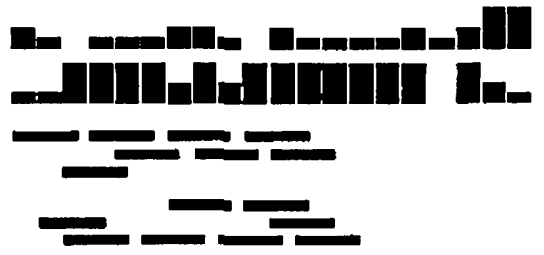

LENFLERLKTIMREKDSKCSS

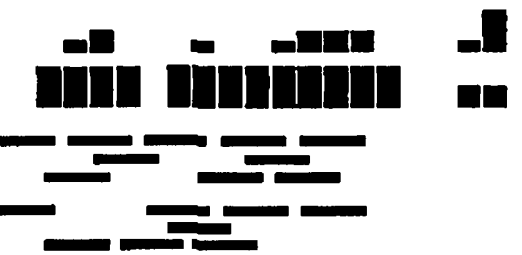

Figure 5. Secondary structure pattern of the wild-type IL-4 and the variants Y124D and Y124G. The NOE are classified according to intensities in NOESY spectra with mixing times of 80 to $100 \mathrm{~ms}$. For the wild-type IL-4, data from 2D-NOESY and the ${ }^{15} \mathrm{~N}$-HMQC-NOESY were used, for the variants only data from unlabelled samples are shown.

residues 121 and 124 and those of the type $\mathrm{NH}_{i} \mathrm{NH}_{i+1}$ between residues 124 and 125 shows that helix $D$ also extends up to $\mathrm{S} 125$ in the variant Y124D. The NOF between L7 and D124 are also observed, although these are somewhat weaker. All other long range NOF are of comparable size (Table 2).

\section{Discussion}

The secondary and overall tertiary structure in both variants is not perturbed, therefore the changes in the activity profile of the mutants Y124G and Y124D are related to interactions of the receptor with the tyrosine side-chain and its environment, potentially RI21 and S125. This is supported by the activity pattern of the Y124 variants. The ability to stimulate cell proliferation drops within the sequence WT, Y124F, $\mathrm{Y} 124 \mathrm{H}>>\mathrm{Y} 124 \mathrm{G}, \quad \mathrm{Y} 124 \mathrm{~K}, \quad \mathrm{Y} 124 \mathrm{~N}>>\mathrm{Y} 124 \mathrm{D}$ (Kruse et al., 1992). The fact that variants with aromatic acids in place of Y124 show nearly wildtype activity and the conservation of the structure in the Y124G and Y124D variants suggests the importance of a hydrophobic region formed by part of the aromatic ring of $\mathrm{Y} 124$ for receptor binding. The mutations do not influence the A-C site of the hormone, which explains the unaltered binding properties. These results are in contradiction to those reported in recent investigations (Bamborough et al., 1993; Powers et al., 1993;
Wlodawer et al., 1993). They proposed that the role of Y124 is to stabilize the surrounding of the helical structure and that the changes in the activity profile observed for Y124G and Y124D are due to a loss of structural integrity in this region. In support of this, mechanisms for breaking a helix through glycine or aspartic acid are known, and a docking of the high-affinity IL-4 receptor model to the A-D site of the hormone did not lead to contacts between the receptor and the environment of Y124.

The functionally important region of the structure, the putative recognition site(s) for the receptor(s), is given by the structurally well defined D-A-C face of the hormone. This is based on the analogy to the growth hormone, and the modified activity of the mutants $\mathrm{E} 9 \mathrm{Q} / \mathrm{K}$ (helix $\mathrm{A}$ ) and R88Q/D (helix C), which showed reduced binding activity (Kruse et al., 1994); the variant Y124D (helix D), which showed a strongly antagonistic activity, and the mutants R121D, Y124G and S125D, which were only partial antagonists. The mutations H1Q, D4N, E26Q, E41Q, E43Q, R47Q, R53Q, H59Q, K61Q, R85Q, E103Q, E114Q, K117Q, K123D, and Sl28D showed no effect. Figure 6 shows a view of the D-A-C helix interface. Amino acid substitutions without any effect are shown in blue, those which resulted in reduced binding activity are coloured yellow, and those which lead to an antagonistic activity profile are coloured red. In light of the model of receptor oligomerization, the A-C face (Figure 6(c)) would 


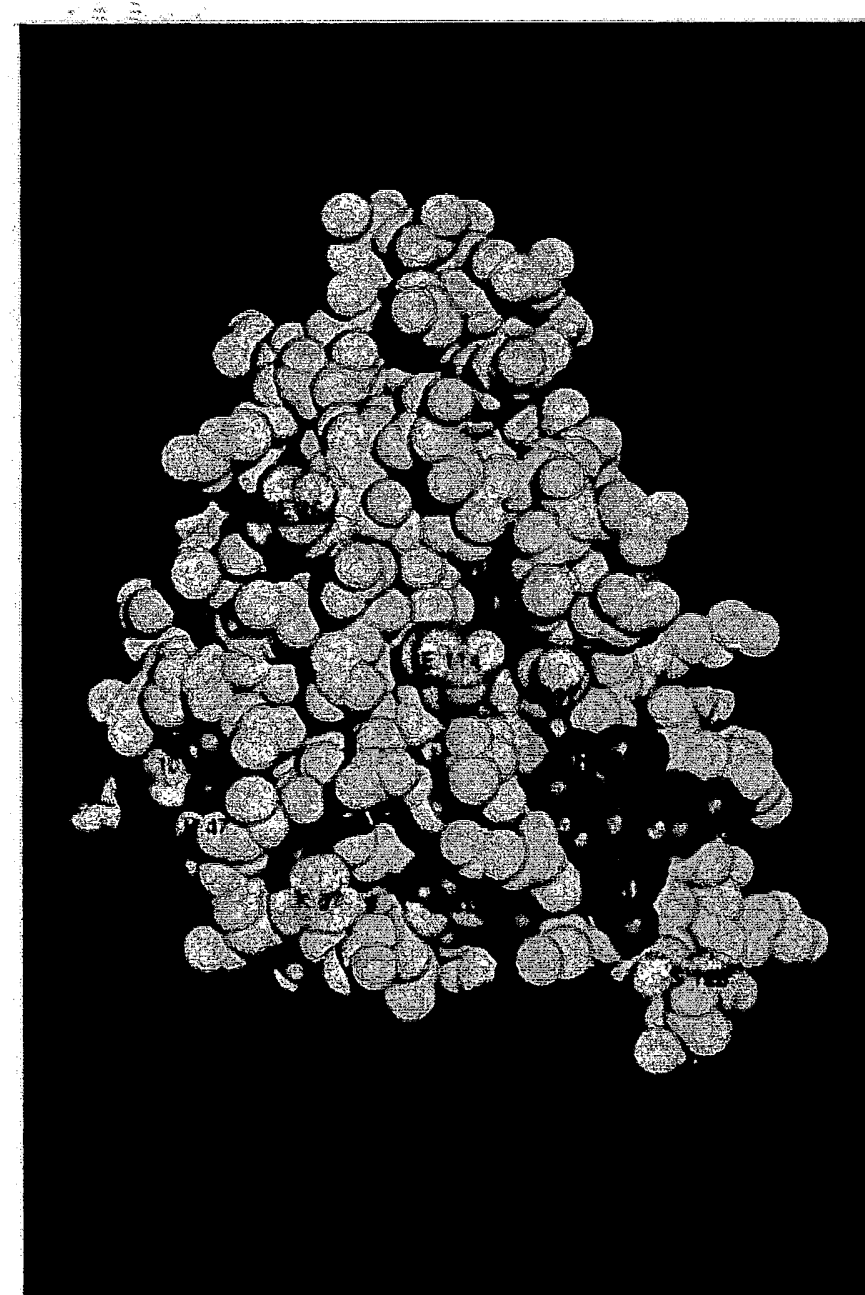

(a)

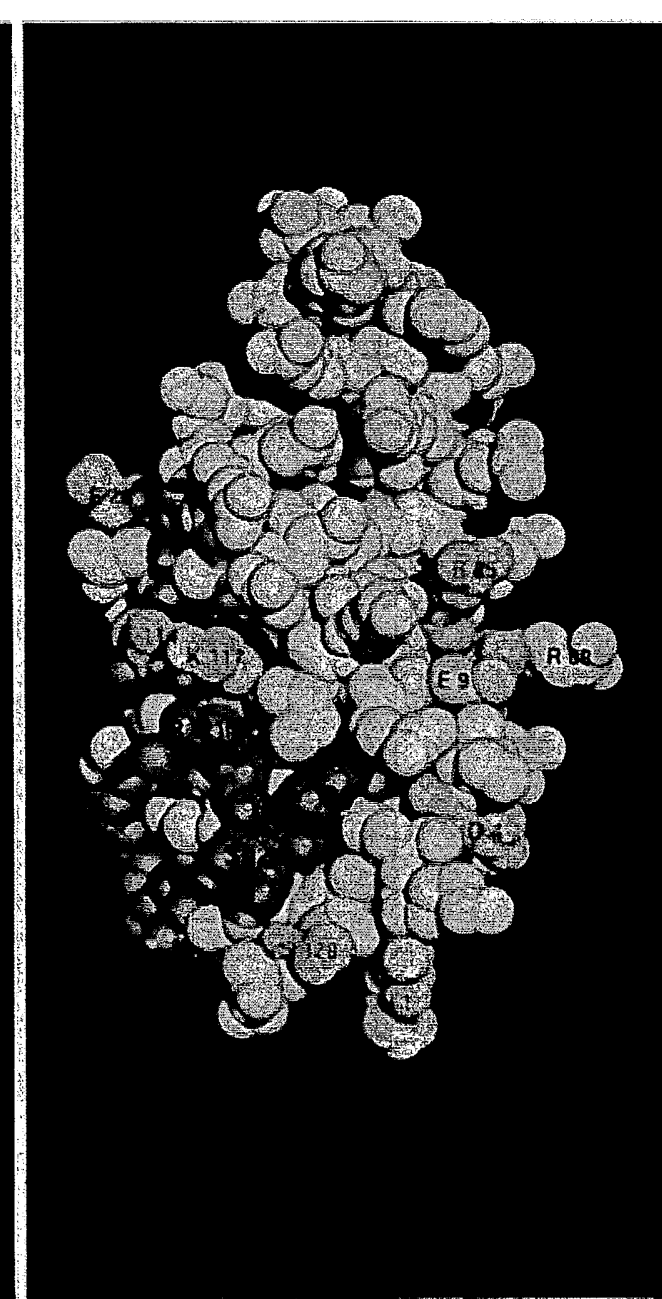

(b)

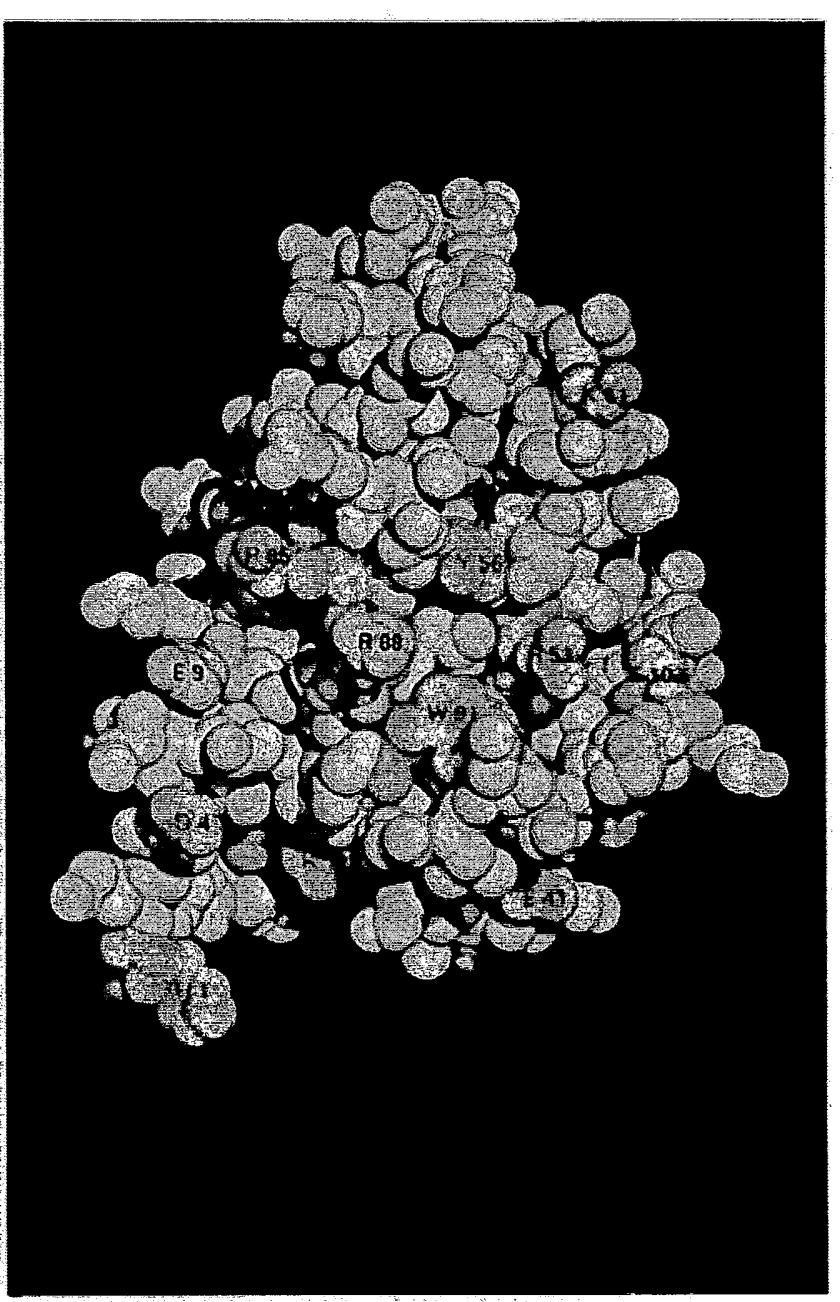

(c)

Figure 6. Space-filling model of IL-4 showing a view onto the D-helix (a), the helices A and D (b), and the helices A and C (c). The sites where mutations did not show any effect are displayed in blue, mutations leading to reduced binding properties are indicated in yellow, and sites where mutations with antagonistic activity were observed are shown in red. 


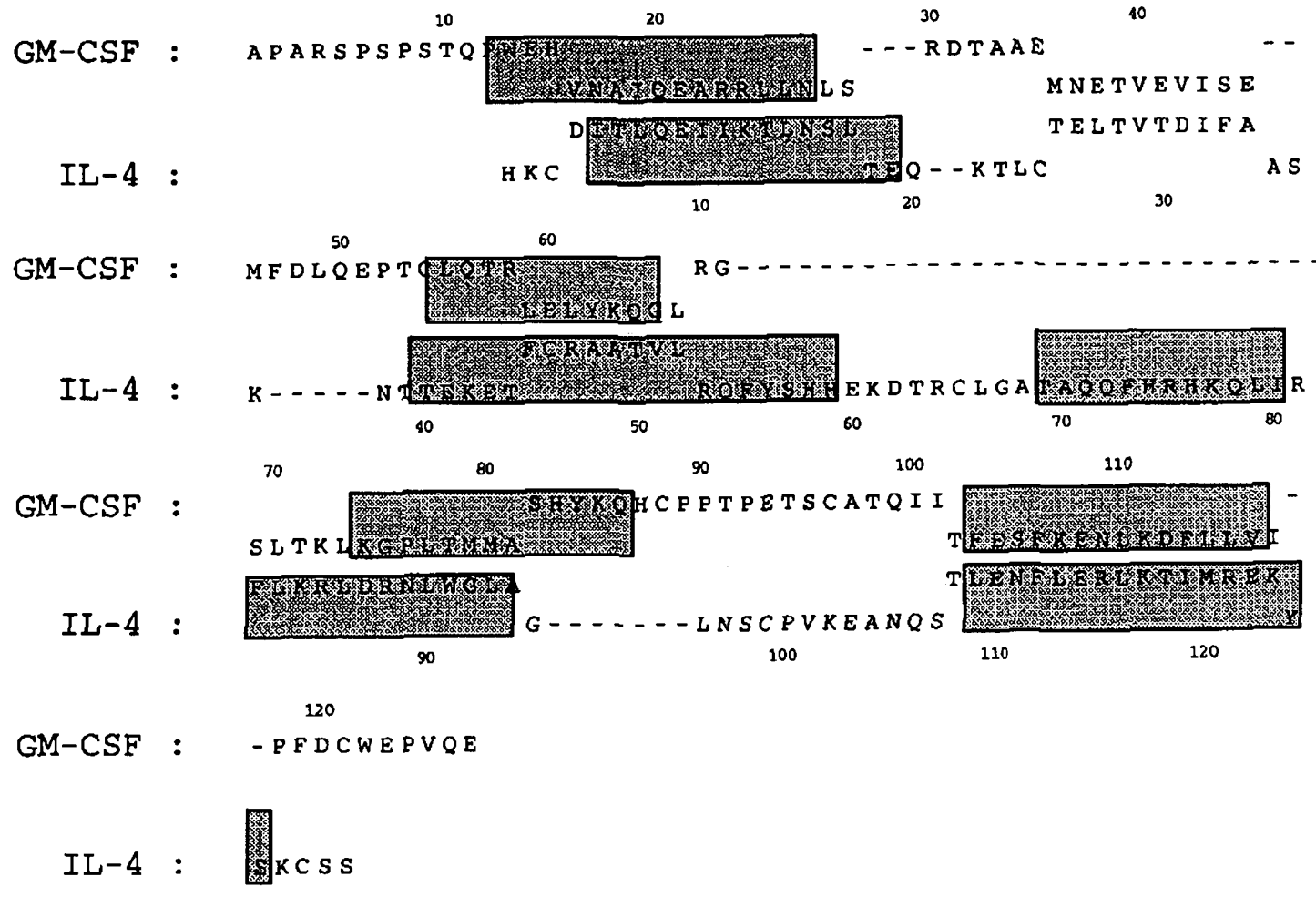

(a)

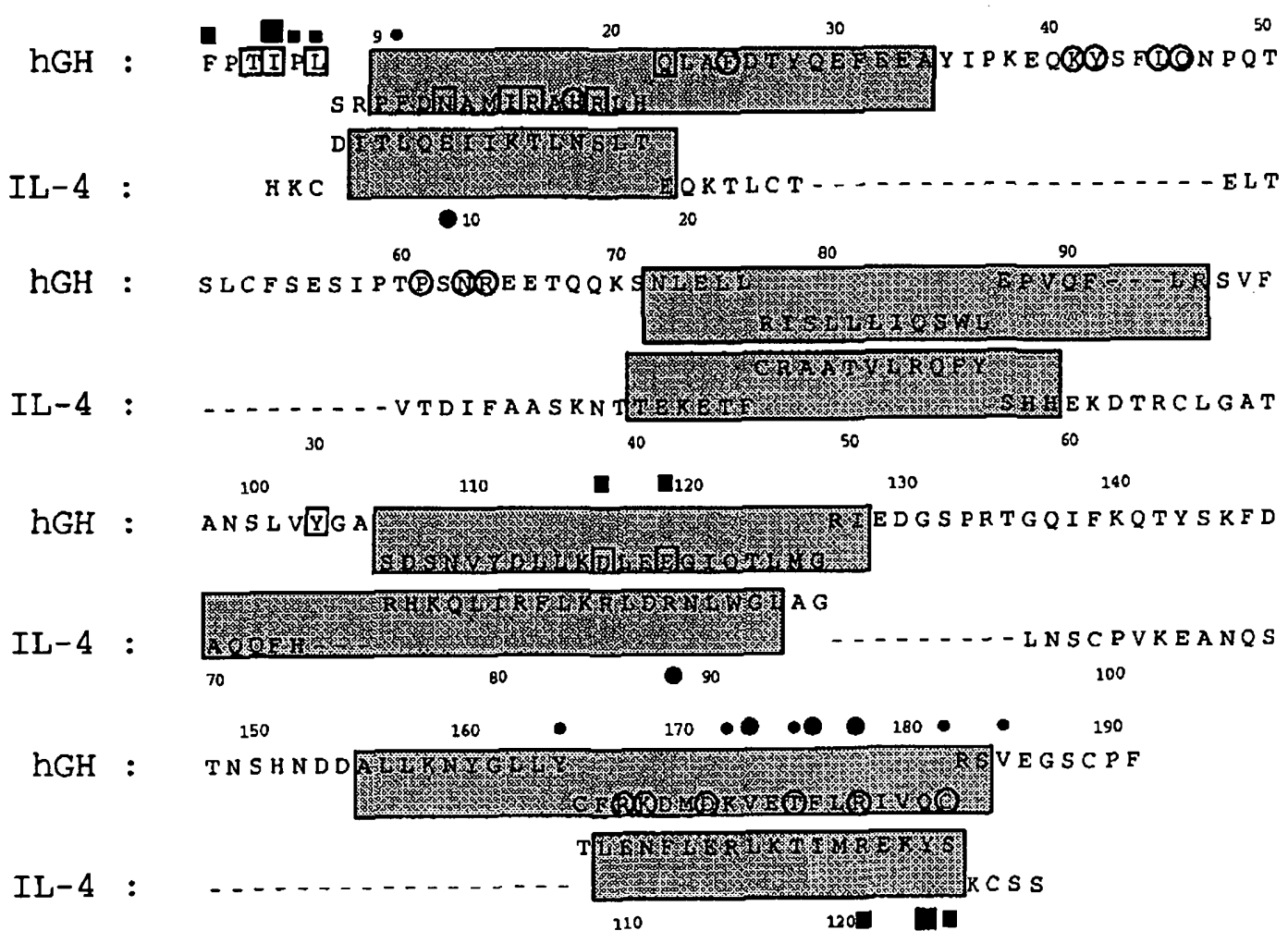

(b)

Figure 7. Sequence alignment of (a) IL-4 and GM-CSF, and (b) IL-4 and hGH derived from a structure comparison using the program WHATIF (Vriend \& Sander, 1991). In the case of the comparison of IL-4 and hGH, an automatic best fit of the structures was generated by maximizing the superposition of common structural elements (Vriend \& Sander, 1991). For those residues which were structurally not further apart from each other than $2 \cdot 0 \AA$, a maximum of sequence identity $(7 \%)$ was obtained. Further support for the sequence alignment deduced from the superposition of the structures is given by the alignment of functionally important residues, i.e. N12 of hGH aligns with E9 of II,-4, as well as 
then be primarily responsible for the binding of the first receptor molecule, whereas the A-D face (Figure 6(a)) would bind the second one, initiate dimerization of the receptor, and hence be responsible for the signal. Surprisingly, the amino acid substitutions leading to an altered activity profile are located in relatively narrow areas.

The mutations on the A-C side of the hormone lead to interesting conclusions concerning the influence of charges and of the electrostatic properties of the surface of the protein. The strongest effects for the E9 and R88 mutants are observed when the charge is reversed. The introduction of a glutamine at either position leads to a noticeable, but not dramatic, effect on the $E C_{50}$ value. It rises from $200 \mathrm{pM}$ to a value of $2000 \mathrm{pM}$ in the case of R88 and $1400 \mathrm{pM}$ for E9. The effect becomes dramatic upon charge reversal $\left(E C_{50}=260,000 \mathrm{pM}\right.$ for E9K and $69,000 \mathrm{pM}$ for R88D) (Kruse et al., 1994). A similar effect is observed for the substitutions of Y124, where the introduction of a negative charge leads to the strongest antagonist. An inspection of the electrostatic properties of the protein surface reveals a very uneven distribution of charged amino acids; the solvent-exposed side of helix $\mathrm{C}$ contains many positively charged residues (K77, R81, K84, R85, and R88) (Wlodawer et al., 1992), while a patch of negatively charged residues is observed in the region around the $\beta$-sheet, the beginning of helix $\mathrm{D}$, and the end of helix $\mathrm{A}$. The negatively charged region is made up of the residues E19, E26, D31, El10 and E114. A comparison of the electrostatic properties of IL-4 with those of other cytokines allows conclusions to be drawn concerning whether two like or two unlike receptor molecules may be bound by the hormone ( $\mathrm{E}$. Demchuk, T. Müller, W. Sebald, H. Oschkinat and R. Wade, unpublished). In fact, the known IL-4 receptor which shows a number of negatively charged residues in the contact area should bind only to the A-C face of IL-4.

The results of the mutation experiments can be compared to other lymphokines by a structure and sequence comparison between IL-4, GM-CSF and hGH. A comparison of hGH and IL-4 is of special interest, as a number of point mutational data on hGH are available (Cunningham \& Wells, 1989, 1991) which may be compared to the mutational data on IL-4, and the structure of the hGH/receptor complex provides a molecular basis for examining hormone-receptor interactions. A comparison seems justified, despite the difference in size between the contact surface of the hGH $\left(4500 \AA^{2}\right)$ and IL-4 $\left(2400 \AA^{2}\right)$, since the A-C face of the IL-4 is of similar size to that in hGH, and the A-D face of IL-4 matches the size of the area important for activity on the A-D side of hGH as defined by site-directed mutagenesis experiments (Cunningham \& Wells, 1989,1991 ).

The comparison of all three structures shows that the individual helices have rather different lengths but the angles between helices $A, C$ and $D$ are very similar. The interhelix angles between these three helices and helix $B$, which seems not to be important for receptor binding, vary to a larger extent.

Comparison between IL-4 and GM-CSF (Figure $7(a))$ shows first of all the major role played by E9 in II -4 and E21 in GM-CSF (Meropol et al., 1992), which in fact are located in the same place in the aligned sequences. For other mutagenesis experiments on GM-CSF the effects are more difficult to explain in terms of receptor-hormone interactions, because they involve either tripeptide deletions (Shanafelt \& Kastelein, 1989), the synthesis of chimeric mouse/human proteins (Kaushansky et al., 1989) or proline scanning (Altmann et al., 1991). In all cases, larger structural rearrangements are expected. An example is the comparison of mutations on helix $\mathrm{C}$, where the IL-4 mutants $\mathrm{R} 88 \mathrm{Q} / \mathrm{D}$ show very different binding properties, and the substitutions $R 85 Q$ and W9IR are rather neutral. The experiments with the chimeric proteins on GM-CSF show that residues in the region 78 to 94 (GM-CSF numbering) (Kaushansky et al., 1989) are responsible for the activity, but the active site cannot be localized further.

An independent comparison between hGH and IL-4 (Figure 7(b)) may be made on the basis of results from mutational studies (see symbols above the sequence of hGH and below the sequence of IL-4) and on the basis of the residues structurally involved in receptor-hormone interactions (de Vos et al., 1992). The latter are indicated within the sequence of hGH. The mutational studies firstly demonstrate that substitutions on the $D$ helix in hGH affect the binding affinity (Cunningham \& Wells, 1989), whereas mutations on that side in IL-4 lead to antagonistic activity, and vice versa for the A-C face. This indicates that the hormones bind the receptor molecules in a different order. Despite this difference, similar interactions with the receptor molecules seem to occur. The binding affinity of

El19 with R88, R178 with Rl21, and Q181 with Y124 of hGH and IL-4. The residues directly involved in receptor binding and the residues found to be important in mutational studies are indicated. An automatic alignment did not yield the highest possible sequence homology for IL-4 and GM-CSF. Therefore, the alignment was performed manually by superimposition of the structures so that the residues not further away from each other than $2.0 \AA$ in both proteins showed a maximum sequential identity. Simultaneously, a good fit was obtained for the common motif in the 2 structures made up by the helices $A$ and $D$, the $\beta$-sheet, and the loops connecting the 2 helices and the sheet. The residues in the superimposed structures which show an r.m.s.d. less than $2.0 \AA$ are printed with a reduced spacing. The mutational data on hGH and IL-4 are included as symbols above or below the sequences. Circles indicate mutations that lead to reduced binding properties, squares indicate sites where mutations produced an antagonistic activity. For hGH, the residues directly involved in receptor binding are indicated within the sequence by circles (first binding receptor molecule) and squares (second receptor molecule). The helical regions are shaded. 
IL-4 to its known receptor is strongly affected by the residues $\mathrm{E9}$ and $\mathrm{R} 88 \mathrm{Q}$, and the corresponding residues $\mathrm{N} 12$ and E119 play a major role in hGH (de Vos et al., 1992; Cunningham \& Wells, 1991). Unexpectedly, substitutions of R85 in IL-4 have no effect, although the corresponding residue in hGH (D1 16) is directly involved in receptor binding via a salt bridge and its replacement by alanine shows larger effects on the activity than a substitution of E119. The role of the $\mathbf{N}$ terminus may be different for both proteins, as the substitution H1Q in IL-4 showed no effect, whereas I4 variants of hGH showed large differences in activity compared to the wild-type.

The epitope on the D-helix defining the area primarily important for the binding of the first receptor molecule in hGH (Cunningham \& Wells, 1989 ) is in a similar position to the site in IL-4, where mutations lead to an antagonistic activity. In fact, the substitution of R12l in IL-4 leads to a result equivalent to the substitution of $R 178$ in hGH. The effects observed for the substitution of Cl82 in hGH are in agreement with those observed for S125 in IL-4. The strong effect observed for Y124 in IL-4 has no correspondence in hGH, which is surprising considering the localized structural effect of the mutations in IL-4 (see above). In the same manner, the neutrality of the substitutions of $\mathrm{K} 117$ in IL-4 is not expected from the comparison with hGH. However, substitution with a negatively charged residue would be expected to show greater effects. An estimate of the interactions of two receptor molecules of the haematopoietin type with IL-4 can be obtained from comparison with the hGH/receptor complex. The site of hGH which binds the first receptor molecule is the A-D face involving the residues $\mathrm{H} 18$ and $\mathrm{F} 25$ on helix $\mathrm{A}$, and R167, K168, D171, T175, R178, and C184 on helix $\mathrm{D}$, neglecting the residues located in the insertion. In IL-4, the residues E110, N111, El14, and T118 should interact with a receptor molecule in addition to R121, Y124 and S125, and hence be potential candidates for generating antagonistic activity. Appropriate substitutions of N15 in IL-4 could have similar effects. The substitution E114Q, however, did not lead to a change in activity of IL-4. The A-C face of hGH contributes the residues T3, I4, L6, N12, L15, R16, R19, Q22, Y103, D116 and E119 to receptor binding. The alignment of the hGH and IL-4 sequences provides an explanation for the finding that the IL-4 mutants E9K and R88D show strongly reduced binding properties. In addition, appropriate substitutions of K12, T13, S16, E19, and R85 should show similar effects. The results allow some conclusions to be made concerning the mode of receptor binding of IL-4. Firstly, the A-C face in IL-4 binds first to a single molecule of the known II, receptor. Secondly, the strong similarity of the A-D side, including the $\beta$-sheet, in IL- 4 and GM-CSF is striking. This could mean that a second receptor molecule, related to the GM-CSF receptor, binds to that side of II -4. Support for this argument comes from the different distribution of charged residues on both sides of the hormone. The surface of helix $\mathrm{C}$ is strongly dominated by positively charged residues, and a large negative region is observed on the A-D side in the area of the $\beta$-sheet, the loops to the helices A and D, and at the beginning of helix $\mathrm{D}$. This suggests that the binding of IL-4 to the known IL-4 receptor, which has negatively charged residues in the proposed binding area (Fernander-Botran \& Vitetta, 1990; Bazan, 1990 c) to this face on IL-4 is implausible.

This work was supported by the Deutsche Forschungsgemeinschaft (grant Se 435/4-1). We thank $H$. Spengler for the preparation of the variant proteins Y124G and Y124G and Dr M. Buehner for helpful discussions. The structures were displayed with QUANTA (Molecular Simulations Inc.).

\section{References}

Altmann, S. W., Johnson, G. D. \& Prystowsky, M. B (1991). Single proline substitutions in predicted alpha-helices of murine granulocyte-macrophage colony-stimulation factor result in a loss in bioactivity and altered glycosylation. J. Biol. Chem. 266, 5333-534l.

Aue, W. P., Bartholdi, E. \& Ernst, R. R. (1976) Two-dimensional spectroscopy. Application to nuclear magnetic resonance. J. Chem. Phys. 64, 2229-2246.

Bamborough, P., Grant, G. H., Hedgecock, C. J. R., West, S. P. \& Richards, W. G. (1993). A computer model of the interleukin-4/receptor complex. Proteins, 17, 11-19.

Bazan, J. F. (1990a). Structural design and molecular evolution of a cytokine receptor superfamily. Proc. Nat. Acad. Sci., U.S.A. 87, 6934-6938.

Bazan, J. F. (1990b). Haemopoietic receptors and helical cytokines. Immunology Today, 11, 350-354.

Bazan, J. F. (1990c). Structural design and molecular evolution of a cytokine receptor superfamily. Proc. Nat. Acad. Sci., U.S.A. 87, 6934-6938.

Boulay, J.-L. \& Paul, W. E. (1992). The interleukin-4 related lymphokines and their binding to hematopoietin receptors. J. Biol. Chem. 267, 20525-20528.

Brünger, A. T. (1992). X-PLOR. A System for X-ray Crystallography and NMR. Yale University Press, New Haven.

Burstein, H. J., Tepper, R. I., Leder, P. \& Abbas, A. K (1991). Humoral immune functions in IL-4 trans genic mice. $J$. Immunol. 147, 2950-2956.

Cabrillat, J., Galizzi, J.-P., Djossou, O., Arai. N., Yokota, T., Arai; K. \& Banchereau, J. (1987). High affinity binding of human interleukin-4 to cell lines. Biochem. Biophys. Res. Commun. 149, 995-1001.

Cantrell, D. A., Collins, M. K. \& Crumpton, M. J. (1988) Autocrine regulation of $\mathrm{T}$-lymphocyte proliferation: differential induction of $\mathrm{Il}-2$ and $\mathrm{Il}-2$ receptor. Immunology, 65, 343-349.

Clore, G. M., Kay, L. E., Bax, A. \& Gronenborn, A. M. (1991). Four dimensional 13C/13C-edited nuclear Overhauser enhancement spectroscopy of a protein in solution: application to interleukin 1b. Biochemistry, $30,12-18$.

Coffman, R. L., Ohara, J., Bond, M. W., Carty, J., Zlotnik, A. \& Paul, W. E. (1986). B-cell stimulatory factor-1 enhances the IgE response of lipopolysaccharide-activated B-cells $J$. Immunol. 136, $4538-4541$. 
Cosman, D., Lyman, S. D., Idzerda, R. I.., Beckman, M. P., Park, L. S., Goodwin, R. G. \& March, C. J. (1990). A new cytokine receptor superfamily. Trends Biochem. Sci. 15, 265-270.

Cunningham, B. C. \& Wells, J. A. (1989). High-resolution epitope mapping of hGH-receptor interactions by alanine-scanning mutagenesis. Science, U.S.A. 244, 1081-1085.

Cunningham, B. C. \& Wells, J. A. (1991). Rational design of receptor-specific variants of human growth hormone. Proc. Nat. Acad. Sci., U.S.A. 88, 3407-3411.

Cunningham, B. C., Ultsch, M., de Vos, A. M., Mulkerrin, M. G., Clauser, K. R. \& Wells, J. A. (1991). Dimerization of the extracellular domain of the human growth hormone receptor by a single hormone molecule. Science, U.S.A. 254, 821-825.

de Vo8, A. M., Ultsch, M. \& Kossiakoff, A. A. (1992). Human growth hormone and extracellular domain of its receptor: crystal structure of the complex. Science, 255, 306-312.

De Vries, J. E., Gauchat, J. F., Aversa, G. G., Punnonen, J., Gascan, H. \& Yssel, H. (1991). Regulation of IgE synthesis by cytokines. Curr. Opin. Immunol. 3, 851-858.

Defrance, T., Vanvesliet, B., Anbry, J. P., Takebe, Y., Arai, N., Miyajima, A., Yokota, T., Lee, F., Arai, K. I., de Vries, J. E. \& Banchereau, J. (1987). B-cell growth promoting activity of recombinant human interleukin-4. J. Immunol. 139, 1135-114I.

Diederichs, K., Boone, T. \& Karplus, P. A. (1991). Novel fold and putative receptor binding site of granulocyte-macrophage colony-stimulating factor. Science, 254, 1779-1782.

Dullens, H. F. \& DeWit, C. L. (1991). Cancer treatment with interleukins 1,4 and 6 and combination of cytokines: a review. In Vivo, 5, 567-570.

Fanslow, W. C., Spriggs, M. K., Rauch, C. T., Clifford, K. N., Macduff, B. M., Ziegler, S. F., Schooley, K. A., Mohler, K. M., March, C. J. \& Armitage, R. J. (1993). Identification of a distinct low-affinity receptor for human interleukin-4 on pre-B cells. Blood, 81, 2998-3005.

Fernandez-Botran, R. \& Vitetta, E. S. (1990). A soluble, high-affinity, interleukin-4-binding protein is present in the biological fluids of mice. Proc. Nat. Acad. Sci., U.S.A. 87, 4202-4206.

Finkelman, F. D., Holmes, J., Katona, I. M., Urban, J. F., Beckmann, M. P., Park, L. S., Schooley, K. A., Coffman, R. L., Mosmann, T. R. \& Paul, W. E. (1990). Lymphokine control of in vivo immunoglobulin isotype selection. Annu. Rev. Immunol. 8, 303-333.

Fukunaga, R., Ishizaka-Ikeda, F., Seto, Y. \& Nagata, S. (1990). Expression cloning of a receptor for murine granulocyte colony-stimulating factor. Cell, 61, 34]-350.

Galizzi, J. -P., Zuber, C. E., Harada, N., Gorman, D. M., Djossou, O., Kastelein, R., Banchereau, J., Howard, M. \& Miyajima, A. (1990). Molecular cloning of a cDNA encoding the human interleukin-4 receptor. Int. Immunol. 2, 669-675.

Garrett, D. S., Powers, R., March, C. J., Frieden, E. A., Clore, G. M. \& Gronenborn, A. M. (1992). Determination of the secondary structure and folding topology of human interleukin-4 using three-dimensional heteronuclear magnetic resonance spectroscopy. Biochemistry, 31, 4347-4353.

Griesinger, C., Otting, G., Wüthrich, K. \& Ernst, R. R. (1988). Clean TOCSY for IH spin system identifica- tion in macromolecules. J. Amer. Chem. Soc. 110 , 7870-7872.

Harada, N., Castle. B. E., Gorman, D. M., Itoh, N., Schreurs, J., Barrett, R. L., Howard, M. \& Miyajima. A. (1990). Expression cloning of a cDNA encoding the murine interleukin-4 receptor based on ligand binding. Proc. Nat. Acad. Sci., U.S.A. 87, 857-861.

Hayashida, K. (1990). Molecular cloning of a second subunit of the receptor for human granulocyte-macrophage colony-stimulating factor (GM-CSF): Reconstitution of a high-affinity GM-CSF receptor. Proc. Nat. Acad. Sci., U.S.A. 87, 9655-9659.

Idzerda, R. L., March, C. J., Mosley, B., Lyman, S. D., Vanden-Bos, T., Gimpel, S. D. \& Din, W. S. (1990). Human interleukin 4 receptor confers biological responsiveness and defines a novel receptor superfamily. J. Exp. Med. 171, 861-873.

Jansen, J. H., Fibbe, W. E., Willemze, R. \& KluinNelemans, J. C. (1990). Interleukin-4. Blut, 60, 269-274.

Jeener, J., Meier, B. H., Bachmann, P. \& Ernst, R. R. (1979). Investigation of exchange processes by two dimensional NMR spectroscopy. J. Chem. Phys. 71, $4546-4553$.

Kastelein, R. A. \& Shanafelt, A. B. (1993). GM-CSF receptor: interactions and activation. Oncogene, U.S.A. 8, 231-236.

Kaushansky, K., Shoemaker, S. G., Alfaro, S. \& Brown C. (1989). Hematopoietic activity of granulocytemacrophage colony stimulating factor is dependent upon two distinct regions of the molecule: functional analysis based upon the activities of interspecies hybrid growth factors. Proc. Nat. Acad. Sci., U.S.A. 86, 1213-1217.

Kruse, N., Lehrnbecher, T. \& Sebald, W. (1991). Site-directed mutagenesis reveals the importance of disulfide bridges and aromatic residues for structure and proliferate activity of human interleukin-4. FEBS Letters, 286, 58-60.

Kruse, N., Tony, H.-P. \& Sebald, W. (1992). Conversion of human interleukin-4 into a high affinity antagonist by a single amino acid replacement. $E M B O J .11$, 3237-3244.

Kruse, N., Shen, B., Arnold, S., Tony, H.-P., Müller, T. \& Sebald, W. (1994). Two distinct functional sites of human interleukin-4 are identified by variants impaired in either receptor binding or receptor activation. $E M B O J .12,5121-5129$.

Marion, D., Kay, L., Sparks, S. W., Torchia, P. A. \& Bax, A. (1989). 3-Dimensional heteronuclear NMR of NI5 labeled proteins. J. Amer. Chem. Soc. 111, 1515-1517.

McKay, I. B. (1992). Response to article: unraveling the structure of I-L-2. Science, 257, 412-413.

Meropol, N. J., Altmann, S. W., Shanafelt, A. B., Kastelein, R. A., Johnson, G. D. \& Prystowsky, M. B. (1992). Requirement of hydrophilic aminoterminal residues for granulocyte-macrophage colony-stimulating factor bioactivity and receptor binding. J. Biol. Chem. 267, 14266-14269.

Morrison, B. W. \& Leder, P. (1992). A receptor binding domain of mouse interleukin-4 defined by a solid phase binding assay and in vitro mutagenesis. $J$. Biol. Chem. 267, 11957-11963.

Mosley, B., Beckmann, M. P., March, C. J., Idzderda, R. L., Gimpel, S. D., VandenBos, T., Friend, D., Alpert, A., Anderson, D. \& Jackson, J. (1989). The murine interleukin-4 receptor: molecular cloning and characterization of secreted and membrane bound forms. Cell, 59, 335-348. 
Mott, H. R., Driscoll, P. C., Boyd, J., Cooke, R. M., Weir, M. P. \& Campbell, I. D. (1992). Secondary structure of hurnan interleukin 2 from 3D heteronuclear NMR experiments. Biochemistry, 31, 7741-7744.

Neidig, K.-P., Saffrich, R., Lorenz, M. \& Kalbitzer, H. R. (1990). Cluster analysis and multiplet pattern recognition in two-dimensional NMR spectra. J. Magn. Reson. 89, 543-552.

Nilges, M., Kuszewski, J. \& Brünger, A. T. (1991). Sampling properties of simulated annealing and distance geometry. In Computational Aspects of the Study of Biological Macromolecules by Nuclear Magnetic Resonance Spectroscopy (Hoch, J., et al., eds), Plenum Press, New York.

Oschkinat, H., Cieslar, C. \& Griesinger, C. (1990). Recognition of secondary structure elements in 3D TOCSY-NOESY spectra of proteins. J. Magn. Reson. 86, 453-469.

Park, L. S., Friend, D., Sassenfeld, H. M. \& Urdal, D. L. (1987). Characterization of the human $B$ cell stimulatory factor 1 receptor. J. Exp. Med. 166, 476-488.

Paul, W. E. (1987). Interleukin 4/B cell stimulatory factor 1: one lymphokine, many functions. FASEB J.1, 456-461.

Paul, W. E. (1891). Interleukin-4: a prototypic immunoregulatory lymphokine. Blood, 77, 1859-1870.

Paul, W. E. \& Ohara, J. (1987). B-cell stimulatory factor1/interleukin-4. Annu. Rev. Immunol. 5, 429-459.

Powers, R., Garrett, D. S., March, C. J., Frieden, E. A. Gronenborn, A. M. \& Clore, G. M. (1992a). 1H, 15N, $13 \mathrm{C}$ and $13 \mathrm{CO}$ assignments of human interleukin-4 using three-dimensional double- and triple-resonance heteronuclear magnetic resonance spectroscopy. Biochemistry, 31, 4334-4346.

Powers, R., Garrett, D. S., March, C. J., Frieden, E. A. Gronenborn, A. M. \& Clore, G. M. (1992b). Three-dimensional solution structure of human interleukin-4 by multidimensional heteronuclear magnetic resonance spectroscopy. Science, 256, 1673-1677.

Powers, R., Garrett, D. S., March, C. J., Frieden, E. A., Gronenborn, A. M. \& Clore, G. M. (1993). The high resolution, three-dimensional solution structure of human interleukin-4 determined by multidimensional heteronuclear magnetic resonance spectroscopy. Biochemistry, 32, 6744-6762.

Redfield, C., Smith, L. J., Boyd, J., Lawrence, G. M. P., Edwards, R. G., Smith, R. A. G. \& Dobson, C. M. (1991). Secondary structure and topology of human interleukin 4 in solution. Biochemistry, 30, 11029-11035.

Redfield, C., Boyd, J., Smith, L. J., Smith, R. A. G. \& Dobson, C. M. (1992). Loop mobility in a four-helixbundle protein: NMR relaxation measurements on human interleukin-4. Biochemistry, 31, 10431-10437.

Sakamaki, K., Miyajima, I., Kitamura, T. \& Miyajima, A. (1992). Critical cytoplasmic domains of the common $\beta$ subunit of the human GM-CSF, IL-3 and IL-5 receptors for growth signal transduction and tyrosine phosphorylation. EMBO J. 11, 3541-3549.

Sanderson, C. J., Campbell, H. D. \& Young, I. G. (1988). Moleciular and cellular biology of eosinophil differentiation factor (interleukin-5) and its effects on human and mouse B cells. Immunol. Rev. 102, 28-50.
Shanafelt, A. B. \& Kastelein, R. A. (1989). Identification of critical regions in mouse granulocyte-macrophage colony-stimulating factor by scanning-deletion analysis. Proc. Nat. Acad. Sci., U.S.A. 86, 4872-4876.

Shanafelt, A. B., Miyajima, A., Kitamura, T. \& Kastelein, R. A. (1991). The amino-terminal helix of GM-CSF and IL-5 governs high affinity binding to their receptors. $E M B O J .10,4105-4112$.

Smith, L. J., Redfield, C., Boyd, J., Lawrence, G. M., Edwards, R. G., Smith, R. A. \& Dobson, C. M. (1992). Human interleukin 4. The solution structure of a four-helix bundle protein. J. Mol. Biol. 224, 899-904

Tepper, R. I., Pattengale, P. K. \& Leder, P. (1989). Murine interleukin-4 displays potent anti-tumor activity in vivo, Cell, 57, 503-512.

Tepper, R. I., Coffman, R. L. \& Leder, P. (1992). An eosinophil-dependent mechanism for the antitumor effect of interleukin-4 Science, 257, 548-551.

Vitetta, E. S., Ohara, J., Myers, C. D., Laylou, J. E., Krammer, P. H. \& Paul, W. E. (1985). Serological, biochemical, and functional identity of $B$ cell-stimulatory factor 1 and $B$ cell differentiation factor for IgG1. J. Exp. Med. 162, 1726-1731.

Vriend, G. \& Sander, C. (1991). Detection of common three-dimensional substructures in proteins. Proteins, $11,52-58$.

Walter, M. R., Cook, W. J., Zhao, B. G., Cameron, R. P., Jr, Ealick, S. E., Walter, R. L., Jr, Reichert, P. Nagabhushan, T. L., Trotta, P. P. \& Bugg, C. E. $(1992 a)$. Crystal structure of recombinant human interleukin-4. J. Biol. Chem. 267, 20371-20376.

Walter, M. R., Cook, W. J., Ealick, S. E., Nagabhushan, T. L., Trotta, P. P. \& Bugg, C. E. (1992b). Three-dimensional structure of recombinant human granulocyte-macrophage colony stimulating factor. J. Mol. Biol. 224, 1075-1085.

Watowich, S. S., Yoshimura, A., Longmore, G. D., Hilton, D. J., Yoshimura, Y. \& Lodish, H. F. (1991). Homodimerization and constitutive activation of the erythropoietin receptor. Proc. Nat. Acad. Sci., U.S.A. 89, 2140-2144.

Weigel, U., Meyer, M. \& Sebald, W. (1989). Mutant proteins of human interleukin 2. Renaturation yield, proliferative activity and receptor binding. Eur. $J$. Biochem. 180, 295-300.

Willker, W. \& Leibfritz, D. (1992). Precise determination of coupling constants with the $J_{H H}$ TOCSY experiment, J. Magn. Reson. 99, 421-429.

Wlodawer, A., Pavlovsky, A. \& Gustchina, A. (1992). Crystal structure of human recombinant interleukin 4 at $2.25 \AA$ resolution. FEBS Letters, 309, 59-64.

Wlodawer, A., Pavlovsky, A. \& Gustchina, A. (1993). Hemopoetic cytokines: similarities and differences in the structures, with implications for receptor binding. Protein Sci., 2, 1373-1382.

Zurawski, S. M. \& Zurawski, G. (1989). Mouse interleukin 2 structure-function studies: substitutions in the first alpha-helix can specifically inactivate p70 receptor binding and mutations in fifth alpha-helix can specifically inactivate p55 receptor binding. $E M B O J .8$, 2583-2590. 